\title{
Models for predicting treatment efficacy of antiepileptic drugs and prognosis of treatment withdrawal in epilepsy patients
}

\author{
Shijun Yang, Bin Wang and Xiong Han ${ }^{*}$
}

\begin{abstract}
Although antiepileptic drugs (AEDs) are the most effective treatment for epilepsy, 30-40\% of patients with epilepsy would develop drug-refractory epilepsy. An accurate, preliminary prediction of the efficacy of AEDs has great clinical significance for patient treatment and prognosis. Some studies have developed statistical models and machinelearning algorithms (MLAs) to predict the efficacy of AEDs treatment and the progression of disease after treatment withdrawal, in order to provide assistance for making clinical decisions in the aim of precise, personalized treatment. The field of prediction models with statistical models and MLAs is attracting growing interest and is developing rapidly. What's more, more and more studies focus on the external validation of the existing model. In this review, we will give a brief overview of recent developments in this discipline.
\end{abstract}

Keywords: Prediction model, Machine learning, Antiepileptic drugs, Drug response, Withdrawal reaction

\section{Background}

Epilepsy is one of the most common neurological diseases and has affected more than 68 million people worldwide [1]. Although antiepileptic drugs (AEDs) are currently the primary treatment option for patients with epilepsy (PWE), about $40 \%$ of PWEs will suffer the consequence of drug-resistant epilepsy (DRE) [2]. According to the International League Against Epilepsy, DRE is defined as the failure to achieve sustained seizure freedom after adequate trials of two tolerated and appropriately chosen AEDs treatments (monotherapies or combination therapies) [3]. The mechanism of DRE is not fully clear and may be related to the sensitivity of drug targets, activity of drug transporters, cytochrome P450, structural neural network, and other potential causes of epilepsy [4]. Abrupt and repetitive seizures may lead to neurobiochemical changes in the brain, cognitive decline, and serious psychological problems in PWEs, which can seriously affect patients' quality of life and cause an increased

\footnotetext{
*Correspondence: hanxiong7589@126.com

Department of Neurology, People's Hospital of Zhengzhou University, Henan Provincial People's Hospital, Zhengzhou 450003, China
}

burden on their families. Accurate prediction of the efficacy of AEDs before the initiation of treatment can reduce the use of ineffective drugs, alleviate patients' pain, and improve the prognosis in patients.

Doctors and patients often find it hard to decide whether to reduce or stop AEDs use. Although PWEs can have better cognitive performances and higher quality of life after AEDs withdrawal, there is also an increased risk of recurrence. To avoid recurrence, many patients decide to put up with the side effects rather than completely withdrawing the AEDs. Therefore, there is an urgent need of effective and practical decisionmaking tools to assist clinicians to establish the course of AEDs treatment and withdrawal, as well as to help realize precise, personalized treatment.

Prediction models can integrate multiple clinical or non-clinical parameters within a certain time to calculate the probability of diagnostic outcomes as well as the disease prognosis. These models can stratify patient risk stratification to support clinical decision-making and improve the prognosis and quality of care for patients [5]. Prediction models are divided into two main categories:

(c) The Author(s). 2021 Open Access This article is licensed under a Creative Commons Attribution 4.0 International License, which permits use, sharing, adaptation, distribution and reproduction in any medium or format, as long as you give

appropriate credit to the original author(s) and the source, provide a link to the Creative Commons licence, and indicate if changes were made. The images or other third party material in this article are included in the article's Creative Commons licence, unless indicated otherwise in a credit line to the material. If material is not included in the article's Creative Commons licence and your intended use is not permitted by statutory regulation or exceeds the permitted use, you will need to obtain permission directly from the copyright holder. To view a copy of this licence, visit http://creativecommons.org/licenses/by/4.0/ 
those based on statistics and those based on machine learning algorithms (MLAs).

The statistical prediction models are those whose development is based on statistics, such as univariate and multivariate logistic regression/COX regression analysis to select prediction variables. The integration of multiple selection variables is used to calculate the probability of a particular diagnosis or disease prognosis [5]. The development of statistical prediction models involves collection of datasets, selection of prediction variables, development of a prediction model, evaluation of the model's performance, internal and external validation, and further update of the model. This type of method can be used to create an easy-to-use prediction scoring system [6]. One example is the Framingham risk score, which is widely used in the public health field for estimating the probability of the occurrence of cardiovascular diseases in an individual within the next 10 years. This model was built based on the traditional prediction variables of age, sex, systolic blood pressure, hypertension treatment, total and high-density lipoprotein cholesterol levels, smoking, and diabetes [7].

With the development of artificial intelligence, machine learning is concerned with algorithm induction to improve model performance by using statistical and computer science approaches, and has shown potentials for industrialization. Machine learning has also been applied to fields like speech recognition, image classification, text translation, and medical care [8] for the detection of critical findings in head computerized tomography scans [9] and the classification of cancer [10]. The machine learning technique is superior to manual assessment by clinical experts in that it has higher accuracy of diagnosis and outcome prediction, and it can also be used for epilepsy, especially for automated seizure detection, analysis of imaging and clinical data, epilepsy localization, and prediction of medical and surgical outcomes [11]. Additional validation techniques, such as the hold-out cross-validation, $k$-fold cross validation, and "leave-one-out method" cross-validation, can be used to estimate the performance of the technique. In the following, we will give a brief overview of the efficacy of statistical prediction models and MLAs for predicting AEDs treatment response and patients' outcome after AEDs withdrawal.

\section{Prediction models for the response to AEDs treatment}

Drug selection mainly relies on official guidelines and clinical experience of doctors, due to the fact that the treatment efficacy varies among individual PWEs. Personalized selection of effective AEDs still remains a big challenge. Some prospective studies have identified certain predictive factors of DRE, such as early onset, sex, duration of epilepsy, multiple seizure types, comorbidities, history of central nervous system infection, cognitive impairment, epilepsy syndrome, presence of structural abnormalities in magnetic resonance imaging (MRI), previous history of status epilepticus, family history of epilepsy, history of perinatal brain injury, and certain electroencephalography (EEG) features [12-15]. The identification and determination of these parameters are the basis for creating a predictive model.

\section{Statistical prediction models}

Based on the statistical method, certain variables can be selected and integrated into a model and a score system can be created for a specific purpose; this type of model has been tested in the field of epilepsy. Boonluksiri et al. [16] enrolled 308 children with epilepsy in a retrospective study, and they selected the age at onset, prior neurological deficits, and abnormal EEGs as variables, and established a scale for predicting DRE in children. The children were then divided into 3 groups depending on the risk of developing DRE: low risk (score $<6$ points), moderate risk (score 6-12 points) and high risk (score $>12$ points), with positive likelihood ratios of 0.5 , 1.8 , and 12.5 , respectively, and an area under the curve (AUC) of 0.76. However, as this retrospective study was conducted in a single center with a small sample size and lacked both internal and external validation, the performance and practicality of this model need further validation. In a previous study [15], we developed a scale for predicting DRE in adult patients with MRI-negative epilepsy [MRI(-)DRE]. The AUC was 0.89 and the risk stratification was given as: low risk ( $0-3$ points), medium risk ( $3-5$ points), and high risk ( $>5$ points). Using this method, the probability of DRE could also be calculated. However, this scale was limited by the retrospective design based on data of 132 patients, so further validation is needed. Latzer et al. [17] created a model to predict DRE in children with cerebral palsy at the Tel Aviv Medical Center in Tel Aviv, Israel and this model was used in a retrospective study including 118 patients. The model was composed of four parameters (low Apgar score at $5 \mathrm{~min}$, neonatal seizures, focal-onset epilepsy, and focal slowing on EEG) and the AUC was 0.84. Although their model helped to identify which patient would achieve better seizure control, the study was performed with a small sample size and the lack of validation makes it difficult to judge the model's performance (Table 1).

In summary, a few comprehensive statistical models with multiple variables have been established for predicting the response to AEDs treatment, but they were weakened by some limitations including the retrospective design, small sample sizes, and the lack of internal and external validation. To address these, more prospective, multi-center studies with large sample sizes are 
Table 1 Statistical prediction models for the response to AEDs treatment

\begin{tabular}{|c|c|c|c|c|c|c|c|}
\hline Study & $\begin{array}{l}\text { Study } \\
\text { design }\end{array}$ & $\begin{array}{l}\text { Prediction } \\
\text { target }\end{array}$ & $\begin{array}{l}\text { Development } \\
\text { cohort }\end{array}$ & Final factors & $\begin{array}{l}\text { Validation } \\
\text { cohort }\end{array}$ & AUC & Stratified risks \\
\hline $\begin{array}{l}\text { Boonluksiri } \\
\text { et al. } 2015 \text { [16] }\end{array}$ & Retrospective & DRE in children & $\begin{array}{l}308 \text { cases in Hatyai } \\
\text { Hospital in Thailand }\end{array}$ & $\begin{array}{l}\text { Age onset, prior neurological } \\
\text { deficits and abnormal EEG }\end{array}$ & No & 0.76 & $\begin{array}{l}\text { low risk: }<6 \text { points; } \\
\text { moderate risk: } 6-12 \\
\text { points; high risk: }>12 \\
\text { points }\end{array}$ \\
\hline $\begin{array}{l}\text { Yang et al. } \\
2019 \text { [15] }\end{array}$ & Retrospective & DRE in adults & $\begin{array}{l}132 \text { cases at Henan } \\
\text { Provincial People's } \\
\text { Hospital in China }\end{array}$ & $\begin{array}{l}\text { EEG before AEDs, history of } \\
\text { CNS infection, initial precipitating } \\
\text { injuries, and more than one } \\
\text { recurrence in the first } 6 \text { months }\end{array}$ & No & 0.89 & $\begin{array}{l}\text { low risk: }<3 \text { points; } \\
\text { moderate risk: } 3-5 \\
\text { points; high risk: }>5 \\
\text { points }\end{array}$ \\
\hline $\begin{array}{l}\text { Latzer et al. } \\
2019[17]\end{array}$ & Retrospective & $\begin{array}{l}\text { DRE in children } \\
\text { with cerebral } \\
\text { palsy }\end{array}$ & $\begin{array}{l}281 \text { children with } \\
\text { cerebral palsy at the } \\
\text { Dana-Dwek Children's } \\
\text { Hospital }\end{array}$ & $\begin{array}{l}\text { Low Apgar score at } 5 \text { min, } \\
\text { neonatal seizures, focal-onset } \\
\text { epilepsy and focal slowing on EEG }\end{array}$ & No & 0.68 & No \\
\hline
\end{tabular}

DRE Drug resistant epilepsy, AUC Area under the curve, EEG Electroencephalogram, MRI Magnetic resonance imaging, CNS Central nervous system

required. In addition, these models need to be verified in multiple centers.

\section{Machine learning algorithms}

MLAs can be used to extract more EEG, imaging, and clinical features of patients to build prediction models and validate performance through the use of more methods. MLAs can also be readily applied in artificial intelligence-based industrialization, an extremely relevant and competitive field today.

UCB Pharma has been actively involved in conducting research on the development and validation of MLA for use in the prediction of AEDs effectiveness in individual PWEs. Devinsky et al. [18] at the New York University Medical Center, based on the UCB-IBM collaboration, explored the application of MLA to construct an algorithm for AEDs prescription. A total of 50, 000 PWEs were retrospectively enrolled in the study and randomly divided into a training group of 40, 000 patients and a testing group of 10, 000 patients. Roughly 5, 000 features were extracted to build the prediction model, which had an AUC of 0.72 and was considered to have a good predictive power. The patients with the model-predicted AEDs regimen had significantly higher survival rates than those who received another treatment. There were large discrepancies in the frequency of use of certain AEDs or their combinations between the modelpredicted AEDs regimens and the actually prescribed regimens. The model performed even better than epileptologists in clinical scenarios of monotherapy with levetiracetam or lamotrigine. Regrettably, only $13 \%$ of the actually prescribed AEDs regimens matched with the regimen chosen by the model. Although this model was based on a large sample size and was applied in clinical practice, an obvious limitation of it is the lack of external validation. Thus it still needs to be further optimized to improve the accuracy. An et al. [19] recently trained and tested three algorithms, i.e. the multivariate logistic regression analysis, the support vector machine, and the random forest algorithm, to identify patients at high risk of DRE. A total of 292, 892 patients met the inclusion criteria for epilepsy; 175,735 of them were assigned to the training cohort and the other 117, 157 were assigned to the test cohort, and 1270 features were screened as predictive factors. The random forest algorithm had an AUC of 0.76 and performed the best of the three models. It could predict the emergence of DRE approximately 2 years in advance before a patient failed two AEDs trials. The drawback of this study was that it was a retrospective study without external validation. Furthermore, the DRE incidence was only $13.1 \%$, which was lower than that in other studies, indicating that the dataset had significant limitations.

A number of pharmacogenomic studies have focused on identifying single nucleotide polymorphism (SNP) markers for predicting the outcomes of AEDs treatments, and some studies have tried to establish certain multi-SNP models to predict the response to AEDs. Petrovski et al. [20] prospectively collected the genetic results of patients with newly diagnosed epilepsy and developed a multi-SNP classification model, based on the $k$-nearest neighbor supervised learning approach, to predict the seizure freedom 1 year after AEDs treatment. Their study included 115 patients: 80\% of them (92 cases) were enrolled in the training cohort and 20\% (23 cases) were enrolled in the validation cohort. Two hundred and seventy-nine candidate genes were involved and five genes [rs658624 (SCN4B), rs678262 (SCN4B), rs2808526 (GABBR2), rs4869682 (SLC1A3), and rs2283170 (KCNQ1)] were selected for the final model. The model showed a good predictive accuracy of $83.5 \%$ in the developmental cohort by cross-validation; its sensitivity and positive predictive values were all above $80 \%$ in the two independent validation cohorts. However, the sample size of this study was small, the external validation was lacking, and the model was derived only from the traits of drug genes while not involving EEGs, MRIs, or other key clinical and demographic characteristics, 
which might affect its predictive performance. Shazadi et al. [21] assessed the validity of Petrovski's algorithm in two UK cohorts of newly diagnosed epilepsy patients, and showed that the multi-SNP prediction model was not predictive for the initial treatment response. They also found that the five SNPs appeared to have an impact on the prescription of carbamazepine or valproate in the UK patients.

Some Chinese researchers have also investigated the use of machine learning techniques to predict AEDs effectiveness. Yao et al. [22] established five classical MLAs (decision tree, random forest, support vector machine, XGBoost, and logistic regression) to predict the outcomes of AEDs treatment in patients with newly diagnosed epilepsy. They prospectively collected information of 287 patients with newly diagnosed epilepsy and followed up the patients for a minimum of 3 years at the Second Affiliated Hospital of Zhejiang University. The patients were classified into the remission group and non-remission group with regard to the outcome of seizure re-occurrence, and the former group was further divided into the early remission group and late remission group. The authors evaluated the performance of the models based on their precision, recall, F1-scores, and AUC values. The results showed that the XGBoost algorithm had the best predictive performance between the remission group and non-remission group, with an F1 score of 0.947 and AUC value of 0.979 , and between the early remission group and late remission group, with an F1 score of 0.836 and AUC value of 0.918 . They claimed that the classified prediction could help doctors make clinical decisions and improve treatment strategies. In our previous study [23], we created a model based on support vector machines (SVM) to predict the possibility of seizure freedom after levetiracetam therapy. In a retrospective study including 46 PWEs treated with levetiracetam, $80 \%$ of the patients were used to establish the SVM model and the other patients were used to subsequently test the model. Before the start of levetiracetam treatment, 11 clinical variables and four EEG parameters (sample entropies of $\alpha, \beta, \theta, \delta$ ) were extracted. Our SVM model showed an accuracy of $72.2 \%$ in a five-fold crossvalidation, an accuracy of $75.0 \%$ in a jack-knife validation, and an accuracy of $67.7 \%$ in a hold-out validation in the training cohort. The prediction accuracy of our model was $90 \%$ in the test cohort, and three different verification methods all showed good reliability. The drawbacks of our model were a lack of external validation and that the data were derived retrospectively from a single center; the sample size was also small. Furthermore, the kernel function and dimension of SVM could also have affected the accuracy of the model. Therefore, this model needs to be optimized and performance must be improved by utilizing a larger dataset (Table 2).

While the development in machine learning technology allows for more algorithms to be created and applied in the field of AEDs treatment, it is currently difficult to use this technology in clinical practice because of its complexity and the inconsistent variables. Specific software or web calculators need to be produced to facilitate clinical use and industrialization of the models.

\section{Prediction models for the outcome of AEDs withdrawal}

About 70\% of newly diagnosed PWEs could achieve seizure freedom following appropriate AEDs therapy [12], but the timing at which to stop AEDs is an important issue that remains a significant challenge for both patients and doctors. Due to the fear of seizure relapse, many PWEs choose to continue AEDs even after experiencing long-term seizure freedom, enduring side effects of the treatment. If PWEs remain seizure free after AEDs withdrawal, their psychological stress and quality of life can be significantly improved. In 2013, the Italian League Against Epilepsy issued guidelines on AED withdrawal in PWEs who had achieved a long period of seizure freedom [24], and these guidelines recommended discontinuation of AEDs treatment after a minimum seizure-free period of 2 years. It has been found that the earlier the drug is discontinued, the higher the chance of seizure recurrence is. Some factors, such as abnormal EEGs, mental retardation, perinatal insults, abnormal neurologic signs, partial seizures, older age of onset, and female sex, can independently increase the risk of seizure relapse. Although the guidelines systematically evaluated certain independent variables for AEDs withdrawal, there was not an integrated and comprehensive model for predicting the outcome of AEDs withdrawal.

\section{Statistical prediction models for AEDs withdrawal}

In 2017, Lamberink et al. [25] established two nomograms to predict the seizure recurrence and seizures in the last year of follow-up after AEDs withdrawal in seizure-free patients. They initially did a systematic review and meta-analysis to identify those studies, and then they invited the author to participate in the research, including 1769 PWEs with ten studies in the end. The adjusted concordance statistics were 0.65 for predicting recurrence and 0.71 for predicting long-term freedom; the calibration plots showed good performance of both models. This model also showed good performance of discrimination and a web-based calculator was subsequently built for practical purposes. The study had a large sample size and the model was representative to a certain extent and had some clinical value. Given that these nomograms were established from a pooled analysis of previously published data, the uniformity of clinical variables was slightly poor and multiple imputations were used to deal with the missing data. Furthermore, there was a lack of external validation. Therefore, the 
Table 2 Machine learning algorithms for the response to AEDs treatment

\begin{tabular}{|c|c|c|c|c|c|c|c|}
\hline Study & $\begin{array}{l}\text { Study } \\
\text { design }\end{array}$ & Prediction target & $\begin{array}{l}\text { Training and } \\
\text { testing cohorts }\end{array}$ & Algorithms & $\begin{array}{l}\text { Predictive } \\
\text { features }\end{array}$ & Performance & $\begin{array}{l}\text { External } \\
\text { validation }\end{array}$ \\
\hline $\begin{array}{l}\text { Devinsky } \\
\text { et al. } 2017 \\
\text { [18] }\end{array}$ & Retrospective & $\begin{array}{l}\text { Choice of AEDs for } \\
\text { individual patients }\end{array}$ & $\begin{array}{l}40,000 \text { patients for } \\
\text { training and } 10,000 \\
\text { patients for testing }\end{array}$ & $\begin{array}{l}\text { Machine learning } \\
\text { algorithm }\end{array}$ & $\begin{array}{l}\text { About } 5000 \\
\text { features }\end{array}$ & AUC of 0.72 & Yes \\
\hline $\begin{array}{l}\text { An et al. } \\
2017 \text { [19] }\end{array}$ & Retrospective & Prediction of DRE & $\begin{array}{l}175,735 \text { were training } \\
\text { cohort and the other } \\
117,157 \text { were test } \\
\text { cohort }\end{array}$ & $\begin{array}{l}\text { Multivariate logistic } \\
\text { regression, support } \\
\text { vector machine and } \\
\text { random forest }\end{array}$ & 1270 features & AUC of 0.76 & No \\
\hline $\begin{array}{l}\text { Petrovski } \\
\text { et al. } 2009 \\
\text { [20] }\end{array}$ & Prospective & $\begin{array}{l}\text { Prediction of AEDs } \\
\text { treatment outcomes }\end{array}$ & $\begin{array}{l}115 \text { patients with } \\
\text { newly diagnosed } \\
\text { epilepsy }\end{array}$ & K-nearest neighbors & $\begin{array}{l}279 \text { candidate } \\
\text { genes }\end{array}$ & $\begin{array}{l}\text { Accuracy of } 83.5 \% \\
\text { and sensitivity } \\
\text { above } 80 \%\end{array}$ & Yes \\
\hline $\begin{array}{l}\text { Yao et al. } \\
2019 \text { [22] }\end{array}$ & Retrospective & $\begin{array}{l}\text { Prediction of AEDs } \\
\text { treatment outcomes }\end{array}$ & $\begin{array}{l}287 \text { patients with } \\
\text { newly diagnosed } \\
\text { epilepsy }\end{array}$ & $\begin{array}{l}\text { Decision tree, random } \\
\text { forest, support vector } \\
\text { machine, XGBoost and } \\
\text { logistic regression }\end{array}$ & $\begin{array}{l}\text { Demographic } \\
\text { features, medical } \\
\text { history, EEG and } \\
\text { MRI }\end{array}$ & $\begin{array}{l}\text { F1 score and AUC } \\
\text { value showed } \\
\text { good performance }\end{array}$ & No \\
\hline $\begin{array}{l}\text { Zhang et al. } \\
2018 \text { [23] }\end{array}$ & Retrospective & $\begin{array}{l}\text { Prediction of } \\
\text { efficacy of } \\
\text { levetiracetam }\end{array}$ & $\begin{array}{l}46 \text { patients with } \\
\text { newly diagnosed } \\
\text { epilepsy }\end{array}$ & $\begin{array}{l}\text { Support vector } \\
\text { machine }\end{array}$ & $\begin{array}{l}\text { Clinical features } \\
\text { and sample } \\
\text { entropy }\end{array}$ & $\begin{array}{l}75.0 \% \text { accuracy in } \\
\text { the training set } \\
\text { and } 90 \% \text { in the } \\
\text { test set }\end{array}$ & No \\
\hline
\end{tabular}

AEDs Antiepileptic drugs, DRE Drug resistant epilepsy, AUC Area under the curve, EEG Electroencephalogram, MRI Magnetic resonance imaging

universality of these nomograms requires further verification by different research teams. Lin et al. [26] from the First Affiliated Hospital of Wenzhou Medical University did an external validation of the Lamberink model. The AUCs for predicting the recurrence and long-term outcomes were 0.71 and 0.68 , respectively. The calibration plots showed that the Lamberink twoyear model had a good fit and, with respect to the decision curve analysis, the Lamberink two-year model also had good performance. Lin's research showed that the Lamberink two-year model may have a greater value in guiding drug withdrawal in adult PWEs than other models.

Lamberink et al. [27] also created two nomograms for individualized prediction of recurrence and longterm outcomes of AEDs withdrawal after pediatric epilepsy surgery. They included 766 children from 15 centers, and the final models were composed of 3-5 factors. The discrimination in terms of adjusted concordance statistic was 0.68 for predicting seizure recurrence and 0.73 for predicting long-term seizure freedom and the calibration plots showed good performance. A visualized prediction tool is also provided online. In addition to the large sample size from multiple centers, the validation of these nomograms was executed well and supported by a webbased calculator. This indicates that these models have high clinical value for recommending the cessation and withholding of AEDs after pediatric epilepsy surgery. However, as there was no external validation, the application of the nomograms in other populations remains to be tested (Table 3).

Table 3 Statistical prediction models for AEDs withdrawal

\begin{tabular}{|c|c|c|c|c|c|c|c|}
\hline Study & $\begin{array}{l}\text { Study } \\
\text { design }\end{array}$ & Prediction target & $\begin{array}{l}\text { Development } \\
\text { cohorts }\end{array}$ & Final factors & $\begin{array}{l}\text { Validation } \\
\text { cohort }\end{array}$ & Adjusted concordance-statistic & Calibration \\
\hline $\begin{array}{l}\text { Lamberink et al. } \\
2017 \text { [25] }\end{array}$ & $\begin{array}{l}\text { Systematic } \\
\text { review and } \\
\text { meta-analysis }\end{array}$ & $\begin{array}{l}\text { Seizure relapse } \\
\text { and long-term } \\
\text { outcomes after } \\
\text { withdrawal of } \\
\text { AEDs }\end{array}$ & $\begin{array}{l}\text { Ten studies } \\
\text { with } 1769 \\
\text { patients }\end{array}$ & $\begin{array}{l}\text { Duration before remission, } \\
\text { seizure-free interval before } \\
\text { AEDs withdrawal, age at } \\
\text { onset, history of febrile } \\
\text { seizures, number of seizures } \\
\text { before remission, epilepsy } \\
\text { syndrome, developmental } \\
\text { delay, EEG before withdrawal, } \\
\text { sex, family history of epilepsy }\end{array}$ & $\begin{array}{l}\text { Internal and } \\
\text { external } \\
\text { validation }\end{array}$ & $\begin{array}{l}0.65 \text { for predicting seizure } \\
\text { recurrence and } 0.71 \text { for } \\
\text { predicting long-term } \\
\text { seizure freedom }\end{array}$ & $\begin{array}{l}\text { Calibration plots } \\
\text { showed good } \\
\text { calibration }\end{array}$ \\
\hline $\begin{array}{l}\text { Lamberink et al. } \\
2018 \text { [27] }\end{array}$ & Retrospective & $\begin{array}{l}\text { Seizure relapse } \\
\text { and outcomes } \\
\text { after AEDs } \\
\text { withdrawal after } \\
\text { pediatric epilepsy } \\
\text { surgery }\end{array}$ & $\begin{array}{l}766 \text { children } \\
\text { from } 15 \\
\text { European } \\
\text { epilepsy } \\
\text { centers }\end{array}$ & $\begin{array}{l}\text { Age at withdrawal, time to } \\
\text { AEDs reduction, preoperative } \\
\text { MRI, postoperative EEG, } \\
\text { completeness of resection } \\
\text { of the anatomical lesion, } \\
\text { average frequency before } \\
\text { surgery, number of AEDs } \\
\text { at surgery }\end{array}$ & $\begin{array}{l}\text { Internal } \\
\text { validation }\end{array}$ & $\begin{array}{l}0.68 \text { for predicting seizure } \\
\text { recurrence and } 0.73 \text { for } \\
\text { predicting eventual } \\
\text { seizure freedom }\end{array}$ & $\begin{array}{l}\text { Calibration plots } \\
\text { showed good } \\
\text { calibration }\end{array}$ \\
\hline
\end{tabular}




\section{Machine learning algorithm for the prognosis after AEDs withdrawal}

There has been no report of MLA use for the prognosis or prediction of recurrence after AEDs withdrawal. Future research is needed.

\section{Conclusion}

Several predictive models for AEDs regimen selection and withdrawal in epilepsy have been developed to facilitate clinical decisions, but there are some common issues caused by small sample size or inconsistent parameters. In future studies, a group of main parameters should be established initially. Then, more prospective, multi-center studies with large sample sizes should be conducted to develop certain predictive models, which can be widely accepted in the field of AEDs treatment in order to improve the prognosis and quality of life of patients with epilepsy.

\section{Abbreviations}

AEDs: Antiepileptic drugs; DRE: Drug refractory epilep\sy; PWE: Patients with epilepsy; MLA: Machine-learning algorithm; EEG: Electroencephalography; AUC: Area under the curve; SNP: Single nucleotide polymorphism; MRI: Magnetic resonance imaging; SVM: Support vector machines

\section{Acknowledgements}

None.

\section{Authors' contributions}

SJY was responsible for study concept, literature review, manuscript composition and revision; BW conducted literature review. $\mathrm{XH}$ was responsible for study concept and manuscript revision and obtained funding. All authors had read and approved the final manuscript.

\section{Funding}

This study was supported by Joint Construction Project of Province and Ministry in Henan Province (Grant number SB201901074).

\section{Availability of data and materials}

Not applicable.

\section{Ethics approval and consent to participate}

Not applicable.

\section{Consent for publication}

The author gives consent for publication.

\section{Competing interests}

The authors declare that they have no conflict of interest.

Received: 27 May 2020 Accepted: 13 November 2020

Published online: 11 January 2021

\section{References}

1. Ngugi AK, Bottomley C, Kleinschmidt I, Sander JW, Newton CR. Estimation of the burden of active and life-time epilepsy: a metaanalytic approach. Epilepsia. 2010;51(5):883-90.

2. Chen Z, Brodie MJ, Liew D, Kwan P. Treatment outcomes in patients with newly diagnosed epilepsy treated with established and new antiepileptic drugs: a 30-year longitudinal cohort study. JAMA Neurol. 2018;75(3):279-86.

3. Kwan P, Arzimanoglou A, Berg AT, Brodie MJ, Allen Hauser W, Mathern G, et al. Definition of drug resistant epilepsy: consensus proposal by the ad hoc Task Force of the ILAE Commission on Therapeutic Strategies. Epilepsia. 2010;51(6):1069-77.
4. Naimo GD, Guarnaccia M, Sprovieri T, Ungaro C, Conforti FL, Andò S, et al. A systems biology approach for personalized medicine in refractory epilepsy. Int J Mol Sci. 2019;20(15):1-15.

5. Shipe ME, Deppen SA, Farjah F, Grogan EL. Developing prediction models for clinical use using logistic regression: an overview. J Thorac Dis. 2019;11(Suppl 4):S574-S84.

6. Han K, Song K, Choi BW. How to develop, validate, and compare clinical prediction models involving radiological parameters: study design and statistical methods. Korean J Radiol. 2016;17(3):339-50.

7. D'Agostino RB, Vasan RS, Pencina MJ, Wolf PA, Cobain M, Massaro JM, et al. General cardiovascular risk profile for use in primary care: the Framingham Heart Study. Circulation. 2008;117(6):743-53.

8. Deo RC. Machine learning in medicine. Circulation. 2015;132(20):1920-30.

9. Chilamkurthy S, Ghosh R, Tanamala S, Biviji M, Campeau NG, Venugopal VK, et al. Deep learning algorithms for detection of critical findings in head CT scans: a retrospective study. Lancet. 2018;392(10162):2388-96.

10. Coudray N, Ocampo PS, Sakellaropoulos T, Narula N, Snuderl M, Fenyö D, et al. Classification and mutation prediction from non-small cell lung cancer histopathology images using deep learning. Nat Med. 2018;24(10):1559-67.

11. Abbasi B, Goldenholz DM. Machine learning applications in epilepsy. Epilepsia. 2019;60(10):2037-47.

12. Ben-Menachem E. Medical management of refractory epilepsy--practical treatment with novel antiepileptic drugs. Epilepsia. 2014;55(Suppl 1):3-8.

13. Perucca $E$, Tomson $T$. The pharmacological treatment of epilepsy in adults. Lancet Neurol. 2011;10(5):446-56.

14. Walsh S, Donnan J, Fortin Y, Sikora L, Morrissey A, Collins K, et al. A systematic review of the risks factors associated with the onset and natural progression of epilepsy. Neurotoxicology. 2017;61:64-77.

15. Yang SJ, He GN, Han X, Wang N, Chen Y, Zhu XR, et al. A scale for prediction of response to AEDs in patients with MRI-negative epilepsy. Epilepsy Behav. 2019;94:41-6.

16. Boonluksiri $P$, Visuthibhan A, Katanyuwong K. Clinical prediction rule of drug resistant epilepsy in children. Epilepsy Res. 2015:5(2):84-8.

17. Tokatly Latzer I, Blumovich A, Sagi L, Uliel-Sibony S, Fattal-Valevski A. Prediction of drug-resistant epilepsy in children with cerebral palsy. J Child Neurol. 2020;35(3):187-94.

18. Devinsky O, Dilley C, Ozery-Flato M, Aharonov R, Goldschmidt Y, Rosen-Zvi $\mathrm{M}$, et al. Changing the approach to treatment choice in epilepsy using big data. Epilepsy Behav. 2016:56:32-7.

19. An S, Malhotra K, Dilley C, Han-Burgess E, Valdez JN, Robertson J, et al. Predicting drug-resistant epilepsy - a machine learning approach based on administrative claims data. Epilepsy Behav. 2018;89:118-25.

20. Petrovski S, Szoeke CE, Sheffield LJ, D'souza W, Huggins RM, O'brien TJ. Multi-SNP pharmacogenomic classifier is superior to single-SNP models for predicting drug outcome in complex diseases. Pharmacogenet Genomics. 2009:19(2):147-52

21. Shazadi K, Petrovski S, Roten A, Miller H, Huggins RM, Brodie MJ, et al. Validation of a multigenic model to predict seizure control in newly treated epilepsy. Epilepsy Res. 2014;108(10):1797-805.

22. Yao L, Cai M, Chen Y, Shen C, Shi L, Guo Y, et al. Prediction of antiepileptic drug treatment outcomes of patients with newly diagnosed epilepsy by machine learning. Epilepsy Behav. 2019;96:92-7.

23. Zhang JH, Han X, Zhao HW, Zhao D, Wang N, Zhao T, et al. Personalized prediction model for seizure-free epilepsy with levetiracetam therapy: a retrospective data analysis using support vector machine. $\mathrm{Br} \mathrm{J}$ Clin Pharmacol. 2018;84(11):2615-24.

24. Beghi E, Giussani G, Grosso S, ludice A, La Neve A, Pisani F, et al. Withdrawal of antiepileptic drugs: guidelines of the Italian League Against Epilepsy. Epilepsia. 2013;54(Suppl 7):2-12.

25. Lamberink HJ, Otte WM, Geerts AT, Pavlovic M, Ramos-Lizana J, Verweg $J$, et al. Individualised prediction model of seizure recurrence and longterm outcomes after withdrawal of antiepileptic drugs in seizure-free patients: a systematic review and individual participant data metaanalysis. Lancet Neurol. 2017;16(7):523-31.

26. Pisani F, Facini C, Pavlidis E, Spagnoli C, Boylan G. Epilepsy after neonatal seizures: literature review. Eur J Paediatr Neurol. 2015;19(1):6-14.

27. Lamberink HJ, Boshuisen K, Otte WM, Geleijns K, Braun KPJ. Individualized prediction of seizure relapse and outcomes following antiepileptic drug withdrawal after pediatric epilepsy surgery. Epilepsia. 2018;59(3):e28-33. 